\title{
The pulmonary circuit dynamics in COVID-19!
}

\author{
Rohan Magoon $^{1}$ D \\ Received: 13 September 2020 / Accepted: 16 October 2020 / Published online: 31 October 2020 \\ (c) Japanese Society of Anesthesiologists 2020
}

Keywords COVID-19 $\cdot$ Outcomes $\cdot$ Pulmonary hypertension $\cdot$ Systemic inflammation

To the Editor:

I read with interest the article by Hirata and Yamakage, focusing the cardiovascular considerations of COVID-19 [1], motivating me to elucidate the underemphasized pulmonary vascular consequences.

While cytokine storm and microcirculatory dysfunction contribute to pulmonary hypertension (PH) in COVID (accentuated by hypoxemia, mechanical ventilation), impact on outcomes is concerning. Pagnesi et al. evaluated 200 COVID-19 patients, to reveal a $12 \% \mathrm{PH}$ incidence, associated with $41.7 \%$ adverse outcome (mortality/ICU admission) compared to $8.5 \%$ in those without PH [2]. COVID in preexisting PH also accounted for $12 \%$ mortality in a US-based survey [3]. Moreover, $\mathrm{PH}$-setting is prone to right ventricular failure with inflammatory myocardial depression worsening the matter $[1,2]$.

COVID-19 can be compounded by PH, wherein perioperative physician needs to modulate the anesthetic-analgesic-ventilation strategies minimizing any deterioration in the pulmonary dynamics, to ensure favorable outcome.

\section{Acknowledgements None.}

This comment refers to the article available online at https://doi. org/10.1007/s00540-020-02852-1.

Rohan Magoon

rohanmagoon21@gmail.com

1 Department of Cardiac Anaesthesia, Atal Bihari Vajpayee Institute of Medical Sciences (ABVIMS), Dr. Ram Manohar Lohia Hospital, Baba Kharak Singh Marg, New Delhi 110001, India
Funding None.

\section{Compliance with ethical standards}

Conflicts of interest The authors declared that they have no conflicts of interest.

\section{Reference}

1. Hirata N, Yamakage M. Cardiovascular considerations for anesthesiologists during the COVID-19 pandemic. J Anesth. 2020. https://doi.org/10.1007/s00540-020-02852-1 (ahead of print)

2. Pagnesi M, Baldetti L, Beneduce A, Calvo F, Gramegna M, Pazzanese V, Ingallina G, Napolano A, Finazzi R, Ruggeri A, Ajello S, Melisurgo G, Camici PG, Scarpellini P, Tresoldi M, Landoni G, Ciceri F, Scandroglio AM, Agricola E, Cappelletti AM. Pulmonary hypertension and right ventricular involvement in hospitalised patients with COVID-19. Heart. 2020;106:1324-31.

3. Lee JD, Burger CD, Delossantos GB, Grinnan D, Ralph DD, Rayner SG, Ryan JJ, Safdar Z, Ventetuolo CE, Zamanian RT, Leary PJ. A survey-based estimate of COVID-19 incidence and outcomes among patients with PAH or CTEPH and impact on the process of care. Ann Am Thorac Soc. 2020. https://doi. org/10.1513/AnnalsATS.202005-5210C (ahead of print)

Publisher's Note Springer Nature remains neutral with regard to jurisdictional claims in published maps and institutional affiliations. 